\title{
IASI-NG
}

Development Status

\section{DEFENCE AND SPACE}

Bertrand CALVEL / Frédéric BERNARD 


\section{Infrared Atmospheric Sounding Interferometer - New Generation}

Programmatic frame

- End user: EUMETSAT

- Customer: CNES (direct contribution of CNES to MetOp-SG)

- Prime Contractor: Airbus Defence and Space

IASI-NG is an infrared Fourier Transform Interferometer working in the 3,6 to $15,5 \mu \mathrm{m}$ waveband for atmospheric sounding. It provides Temperature and Humidity data vs. altitude, Atmospheric Chemistry data and Climate Variable monitoring. It is one of the payloads on-board the METOP-SG satellite A.

\begin{tabular}{|c|c|}
\hline Sounding Pixel Size & $12 \mathrm{~km}$ \\
\hline Pupil size & $92 \mathrm{~mm}$ diameter \\
\hline Instrument FOV & $\begin{array}{l}5.7 \times 5.7 \mathrm{deg}^{2} \\
84 \times 84 \mathrm{~km}^{2}\end{array}$ \\
\hline $\begin{array}{l}\text { Across track scan } \\
\text { range }\end{array}$ & $98^{\circ}$ \\
\hline Spectral resolution & $\begin{array}{l}0.25 \mathrm{~cm}-1 \\
\text { ( } 2 \text { times better than IASI) }\end{array}$ \\
\hline $\begin{array}{l}\text { Radiometric } \\
\text { Performance }\end{array}$ & $\begin{array}{l}\text { NedT } \sim 0.1 \mathrm{~K} \\
(2 \text { times better than IASI) }\end{array}$ \\
\hline $\begin{array}{l}\text { Radiometric } \\
\text { Calibration }\end{array}$ & $\begin{array}{l}\text { NedT } \sim 0.25 \mathrm{~K} \\
(2 \text { times better than IASI) }\end{array}$ \\
\hline
\end{tabular}

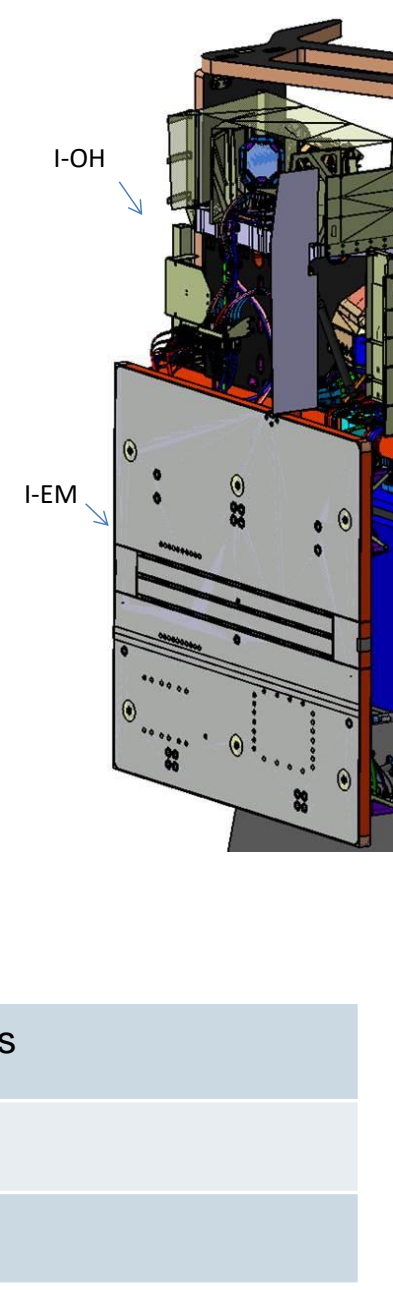

\begin{tabular}{|l|l|}
\hline Lifetime & 7.5 years \\
\hline Mass & $430 \mathrm{Kg}$ \\
\hline Power & $530 \mathrm{~W}$ \\
\hline
\end{tabular}


e

cnes . . 


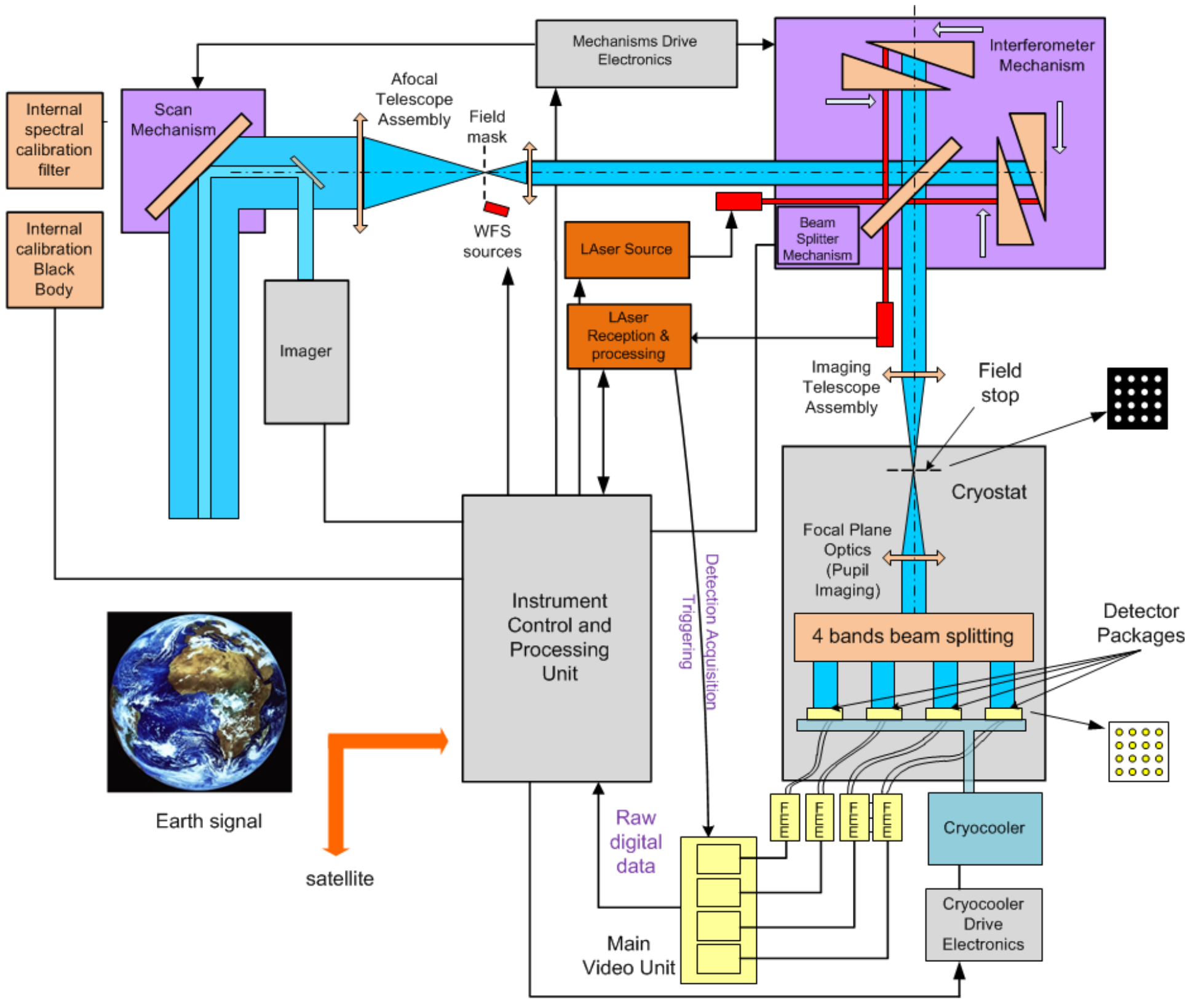



Infrared Atmospheric Sounding Interferometer - New Generation

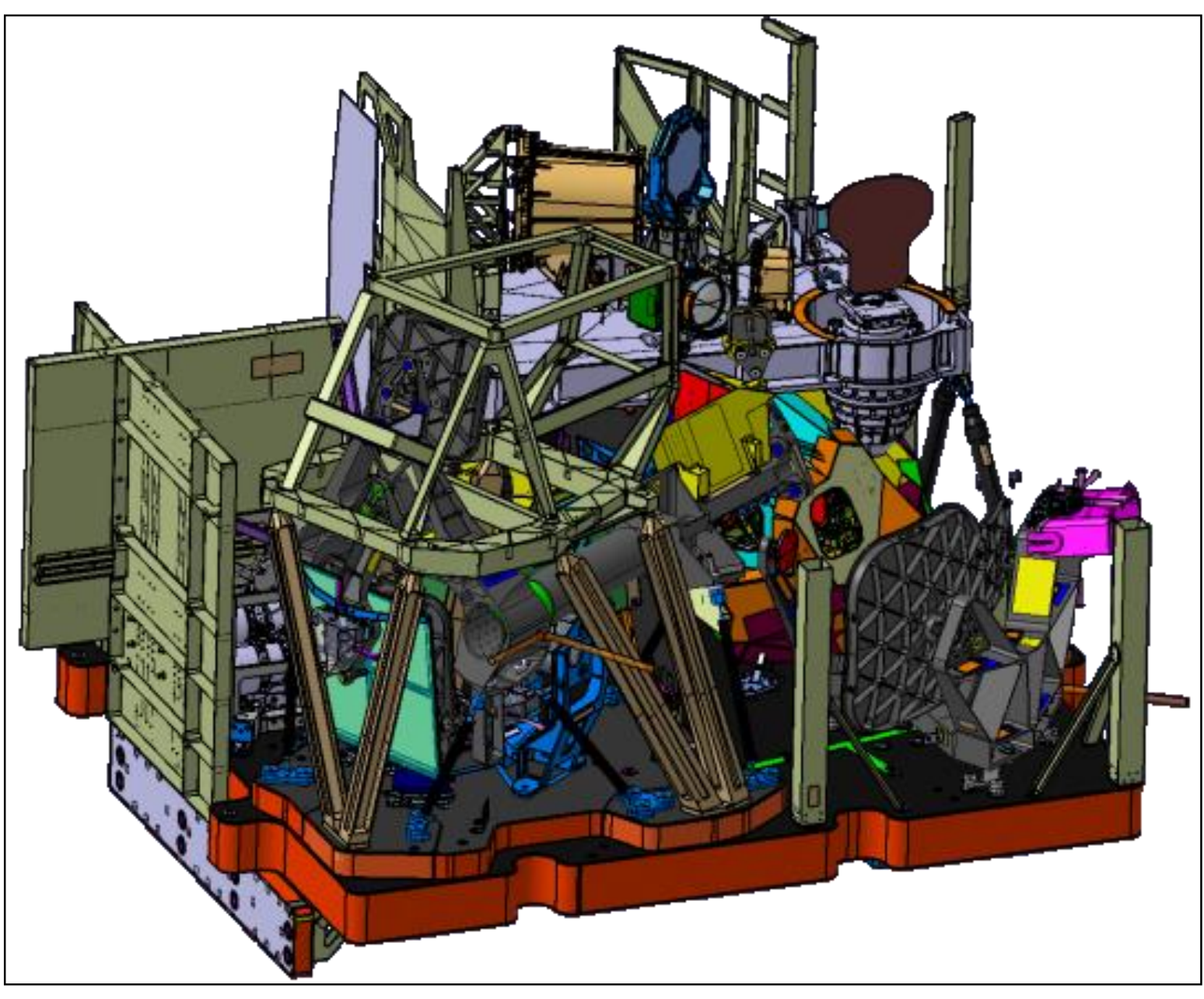

Optical Head

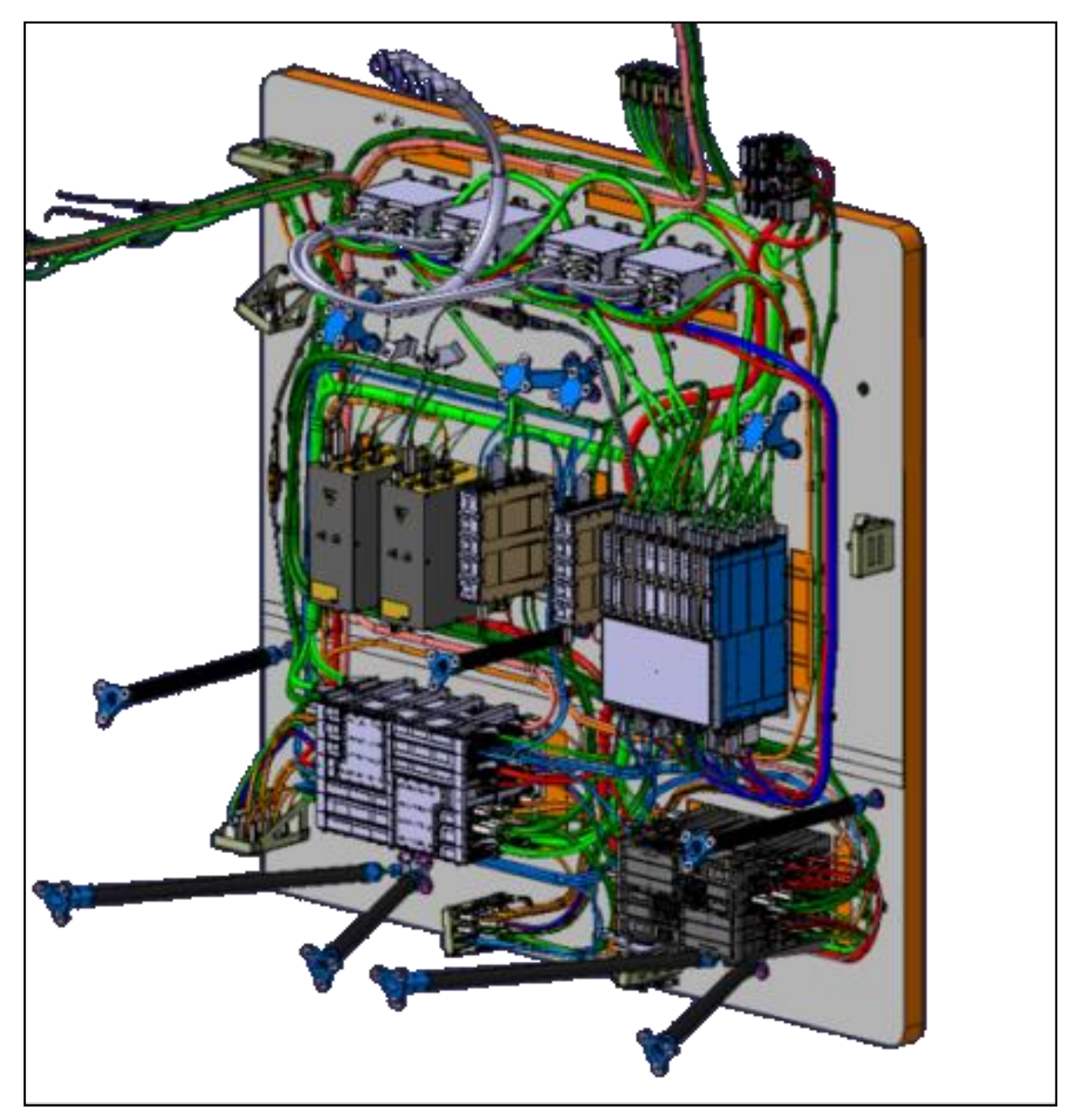

Electronics Module

. c cos . 


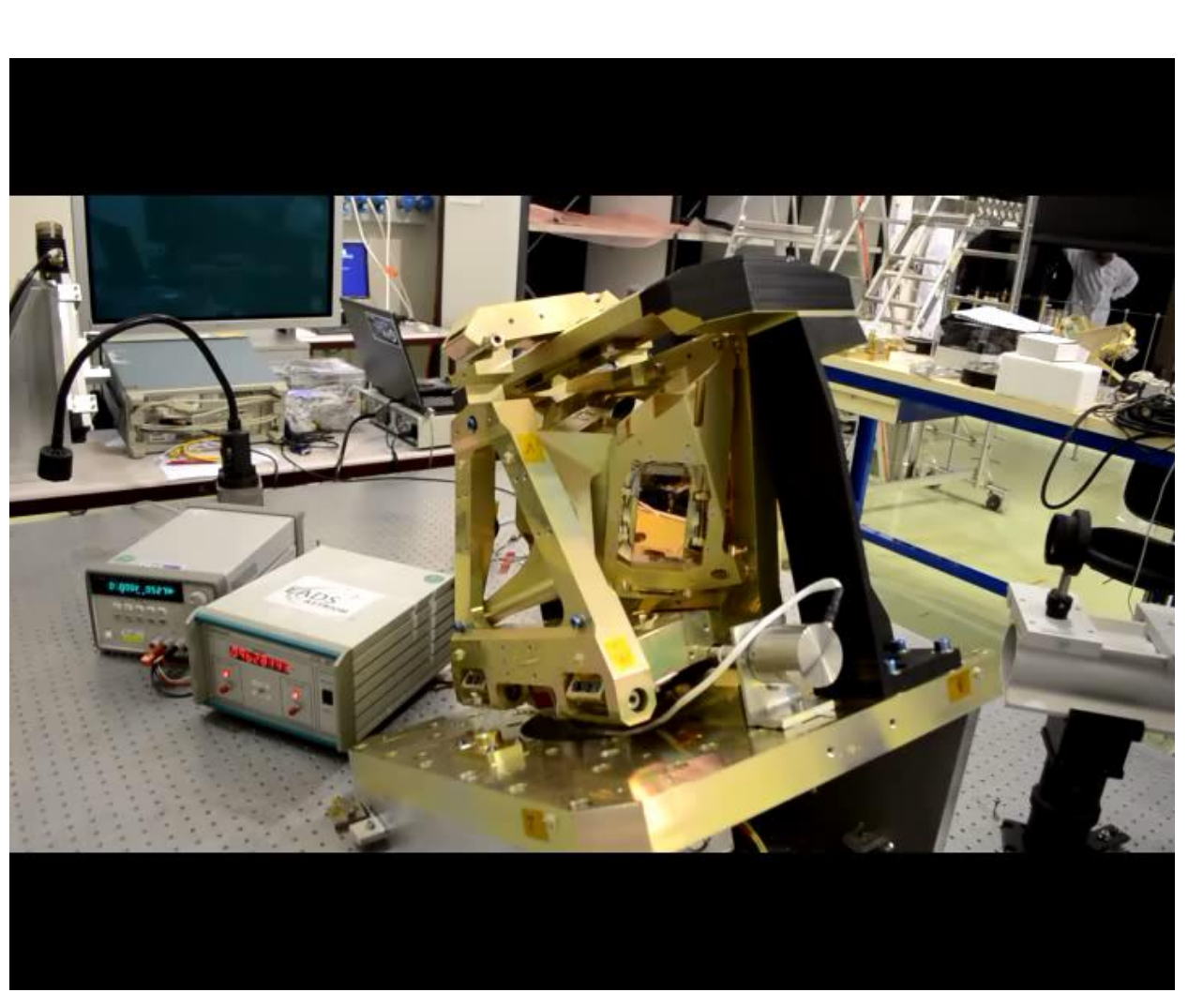

Breadboard Model: actual scan speed

\section{En} Pivot locations and axes are aligned
within 5 microns
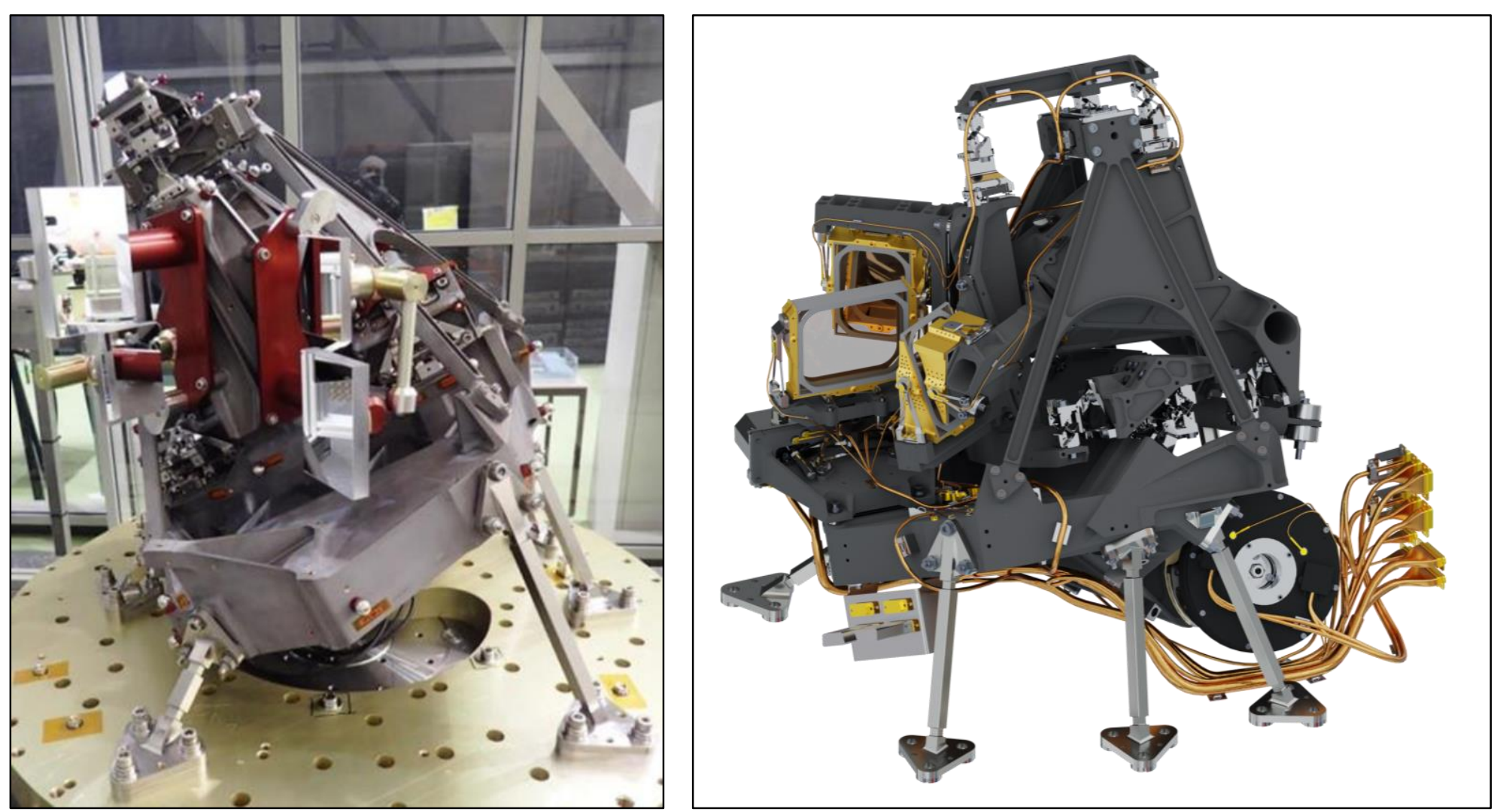

Flight Model realistic rendering

The interferometer is designed and integrated by Airbus DS. 

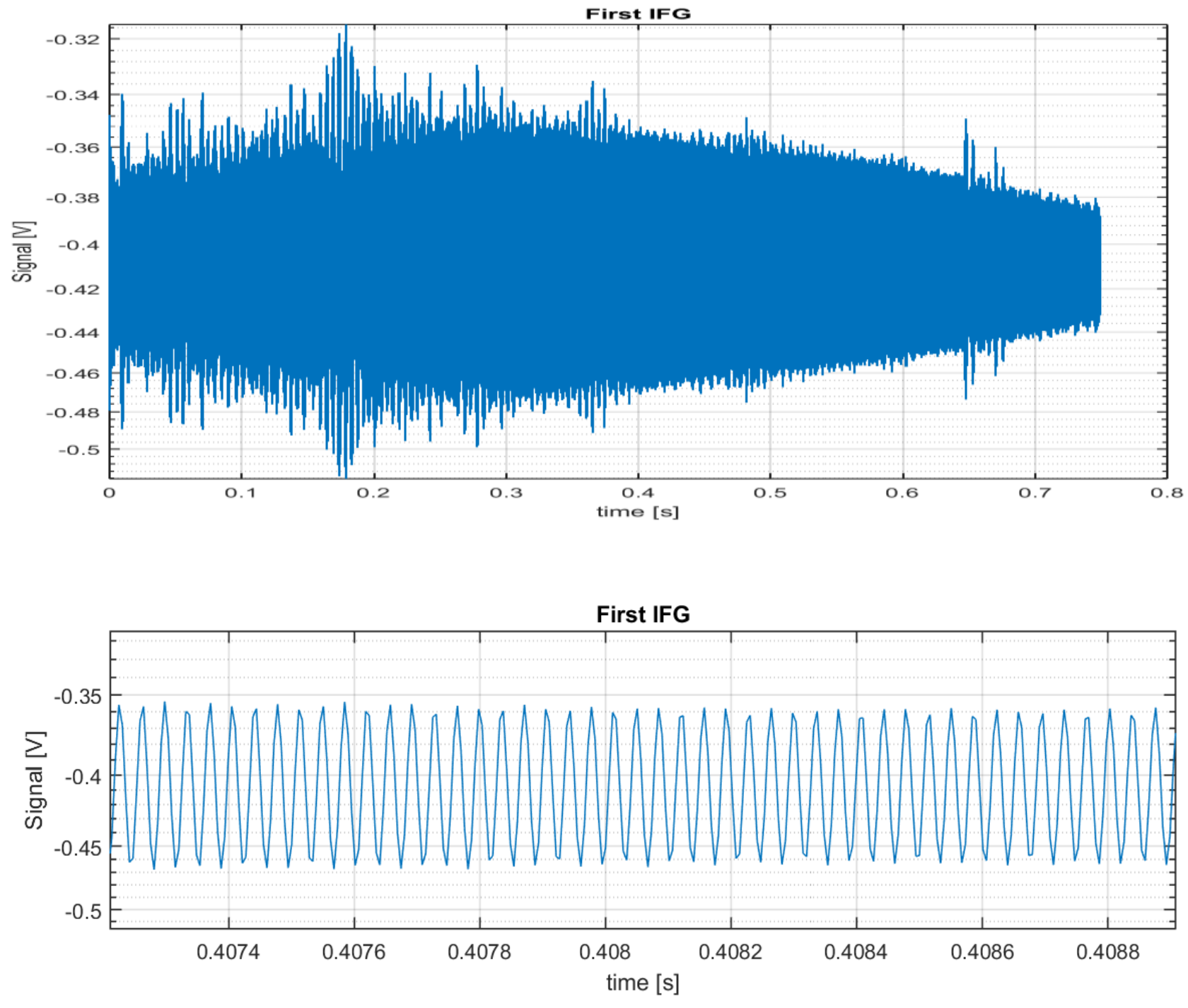

$4 \mu \mathrm{m}$ laser interferogram acquired by the interferometer breadboard

The apodisation is due to varying tilts and wavefront variations during the stroke 



Samples before/after environment tests

Alignment of a $\mathrm{KBr}$ interferometer prism in its mount

- The refractive material used for the Mertz interferometer is Potassium Bromide ( $\mathrm{KBr}$ ) chosen for its good transmission over the needed IR waveband.

- This material has unfortunately poor mechanical properties and is sensitive to humidity.

- A complete qualification program has therefore been set up and successfully completed this year.

- Excellent polishing performances were achieved by REOSC on both prisms and beam splitter blades. 


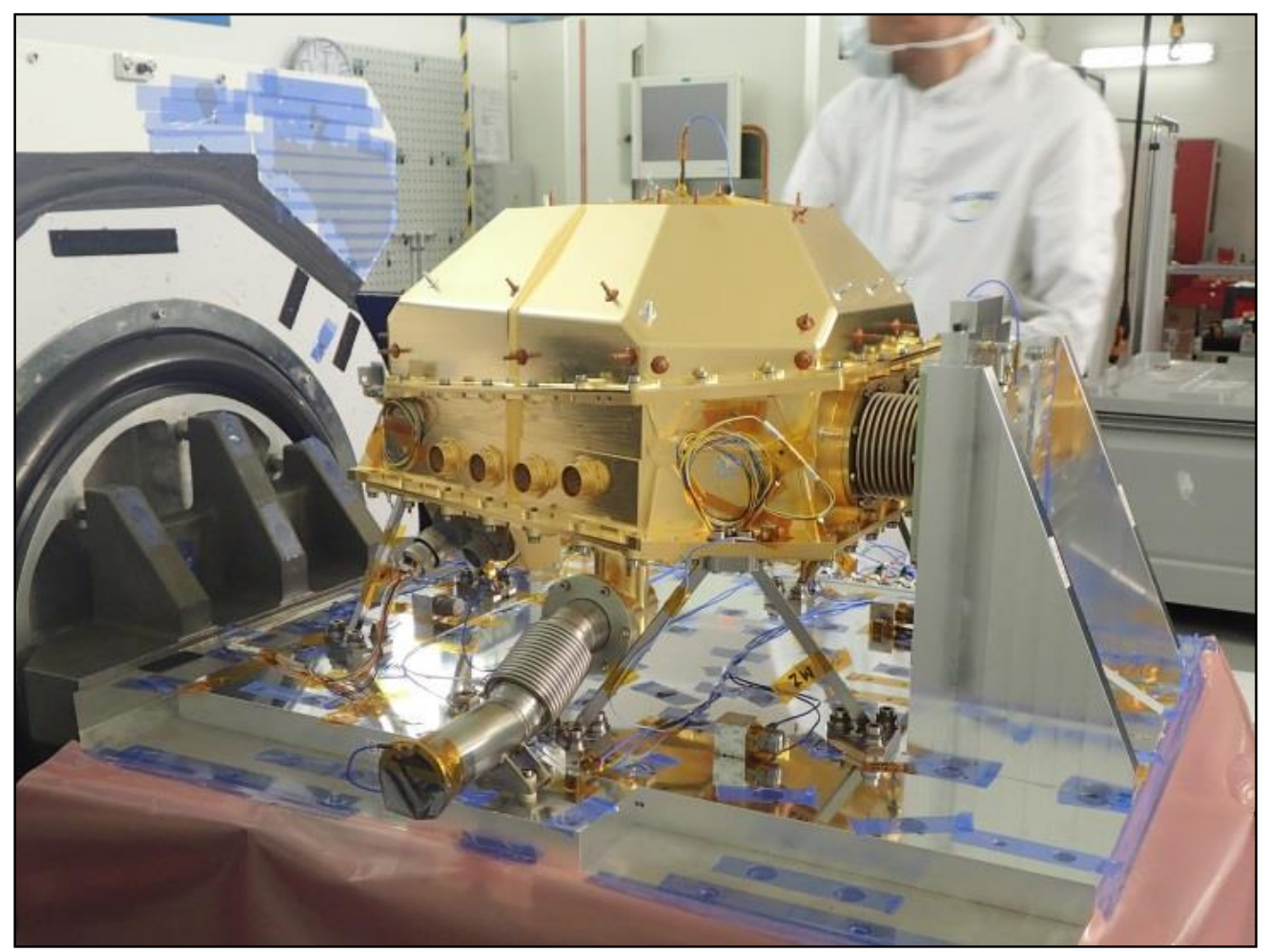

Equipped cryostat under vibration testing

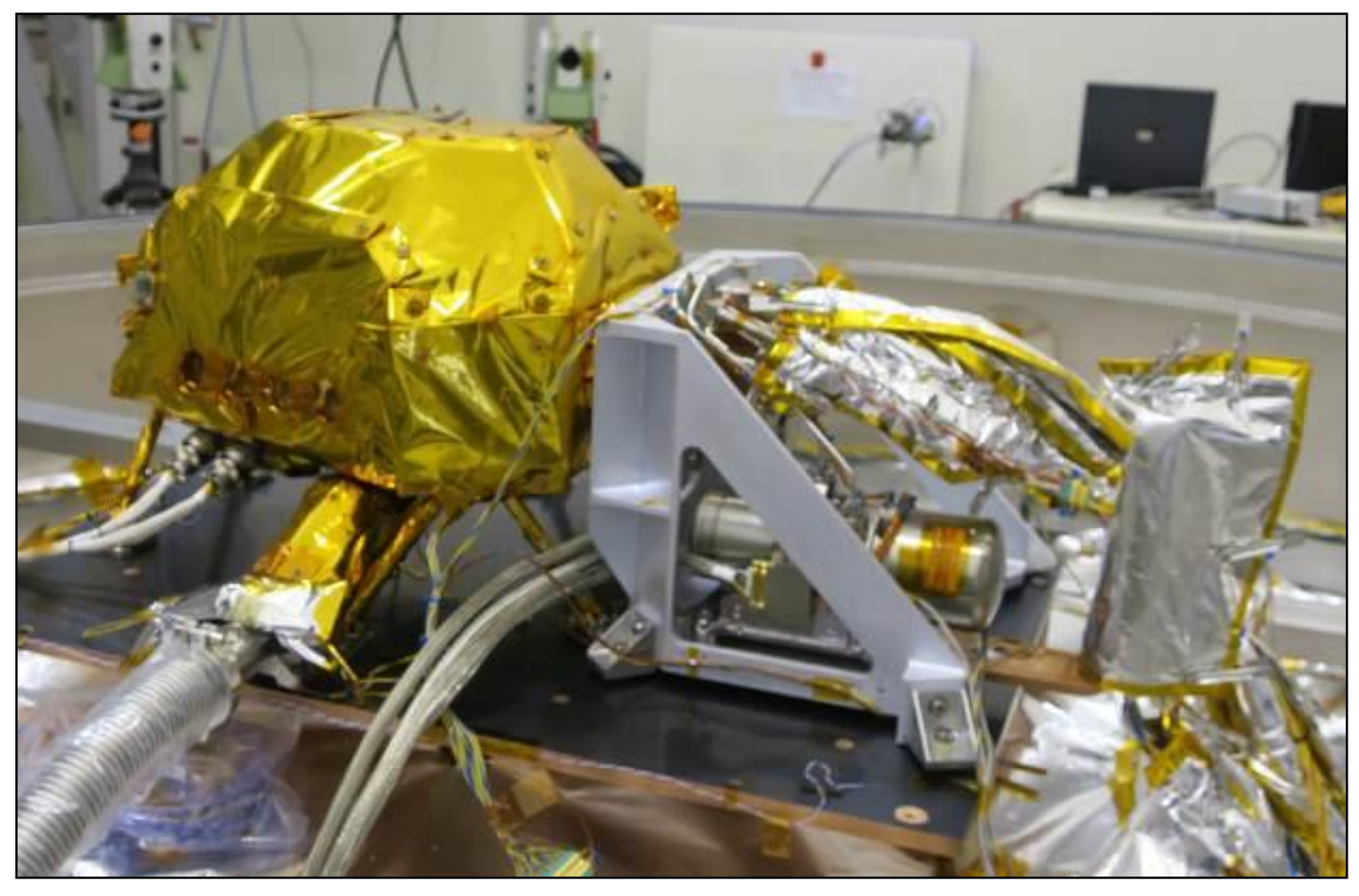

Equipped cryostat under thermal vacuum testing

Cryostat mass $=22 \mathrm{~kg}$, first eigen-frequency $=110 \mathrm{~Hz}$

Detector temperature $=75 \mathrm{~K}$, optical bench temperature $=80 \mathrm{~K}$, extracted power $=3.35 \mathrm{~W}$, used power $=120 \mathrm{~W}$

The FPCA is designed and integrated by Airbus DS. The cryo-cooler system is manufactured by ALAT. 


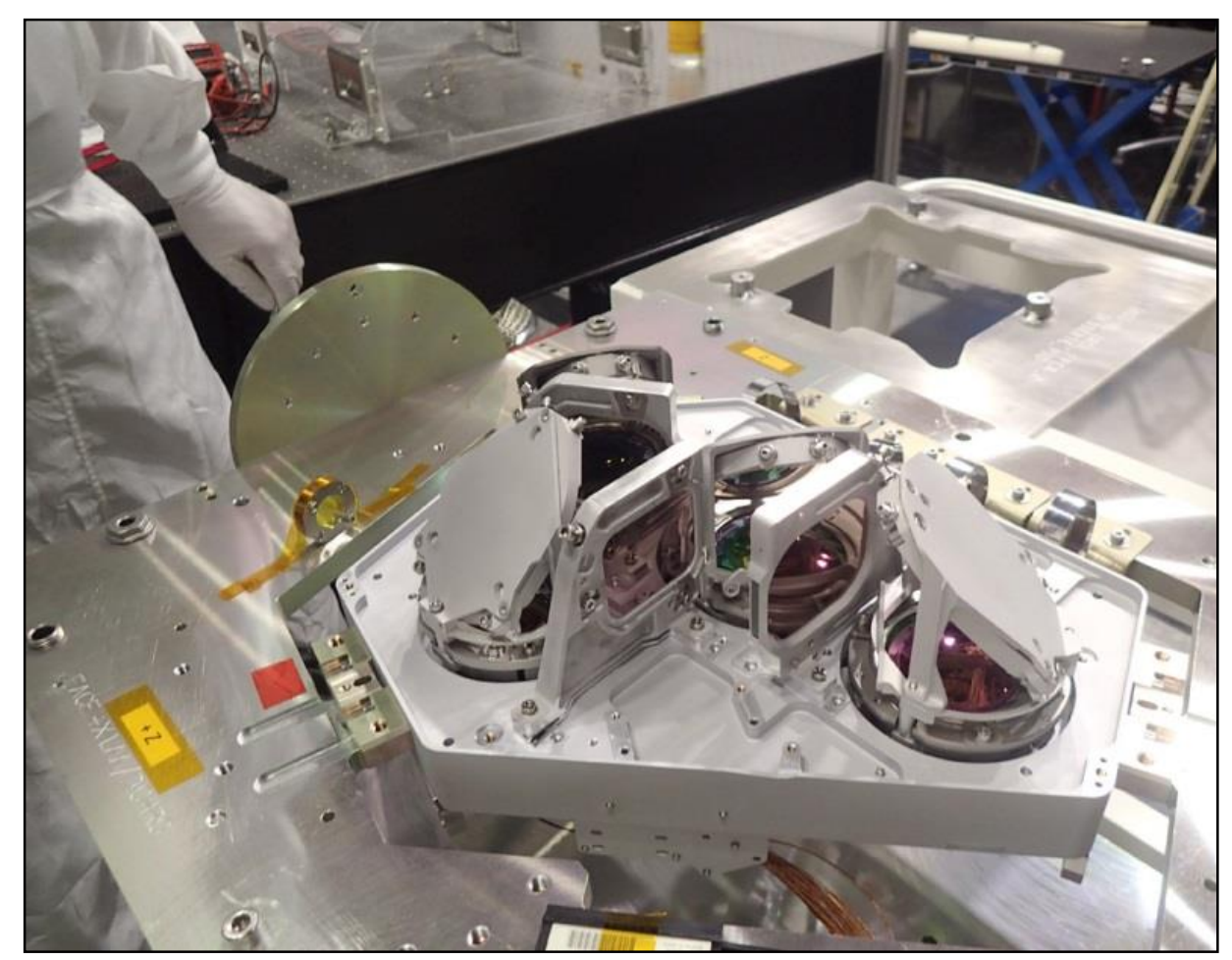

Optical Bench with Dichroics, Folding Mirrors and Pupil Imaging Optics.

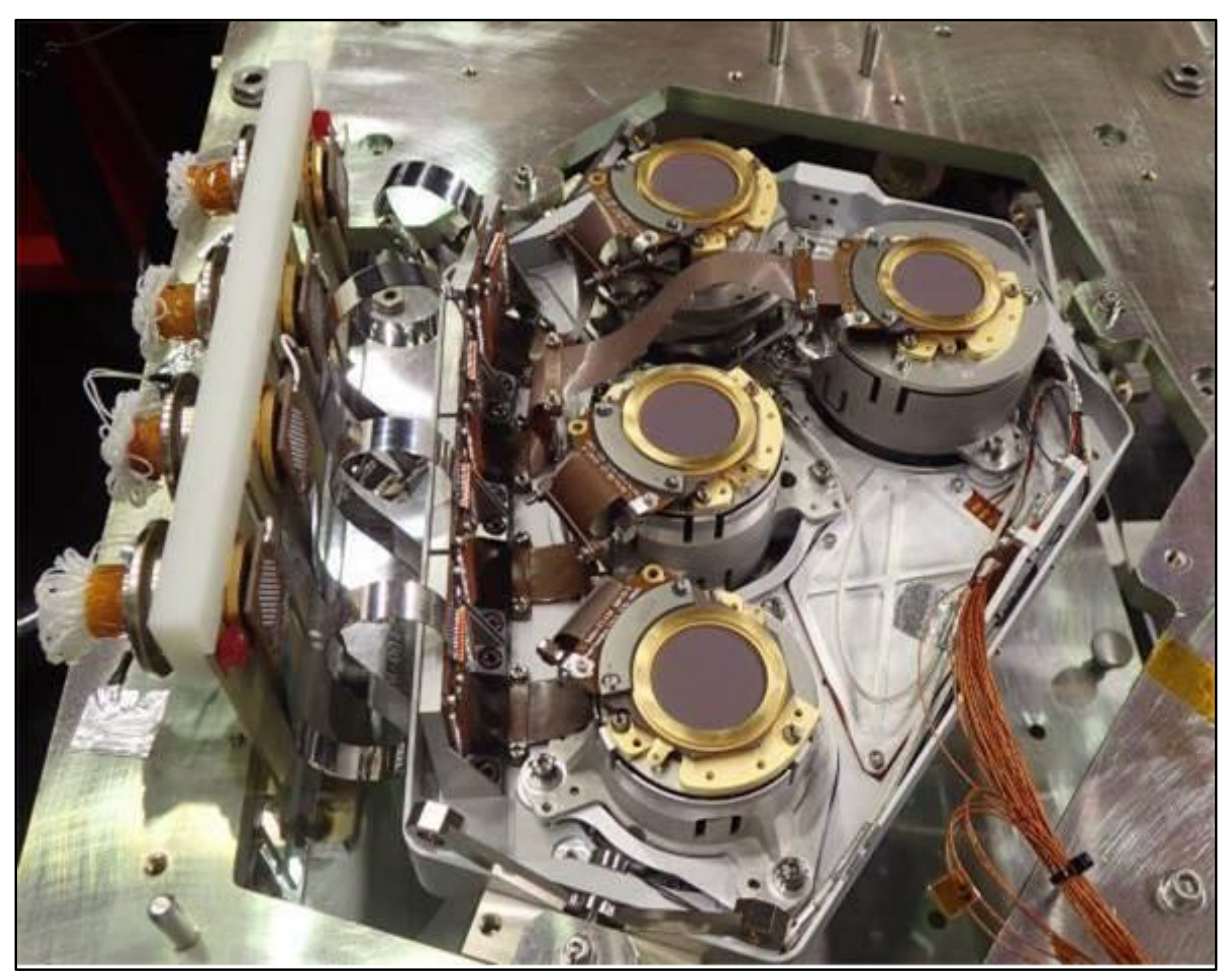

Optical Bench with IR Detectors and Cold Wiring.

All optical mounts are designed and aligned by Airbus DS. Optics materials include ZnSe, CdTe and silica.

The mounts have been designed to withstand vibration testing and cooling down to $80 \mathrm{~K}$ with positioning accuracies in the order of 10 microns. This performance has been demonstrated by tests. 


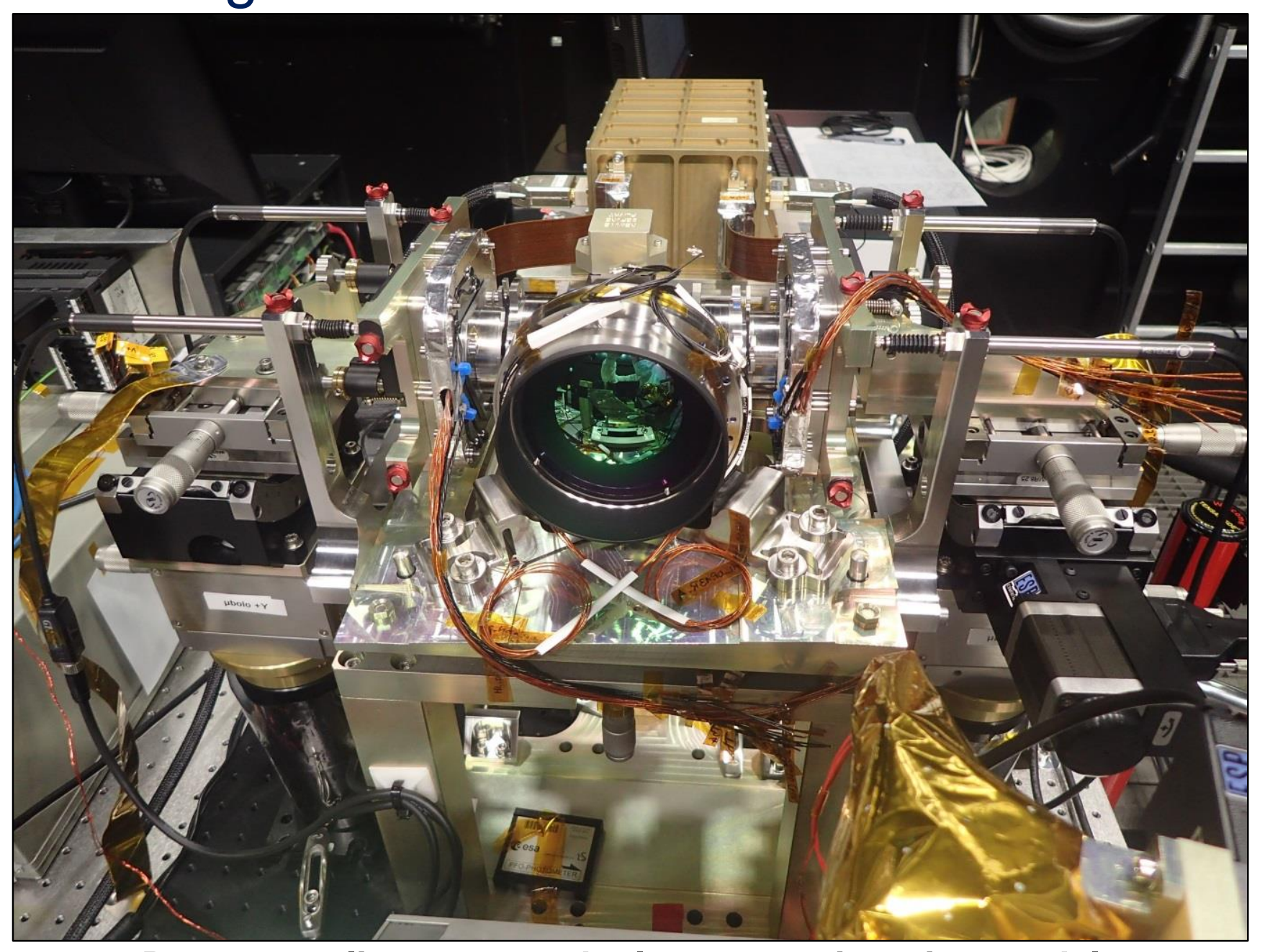

Detectors alignment on the Imager engineering model.

The Imager uses micro-bolometer detectors (manufactured by ULIS) working at ambient temperature. The optics have been manufactured by SODERN.

de

- cnes... 


\section{DeFence And SPACE Scan mechanism}



Closed loop control of the scan law with the Engineering Model Scan Mechanism.
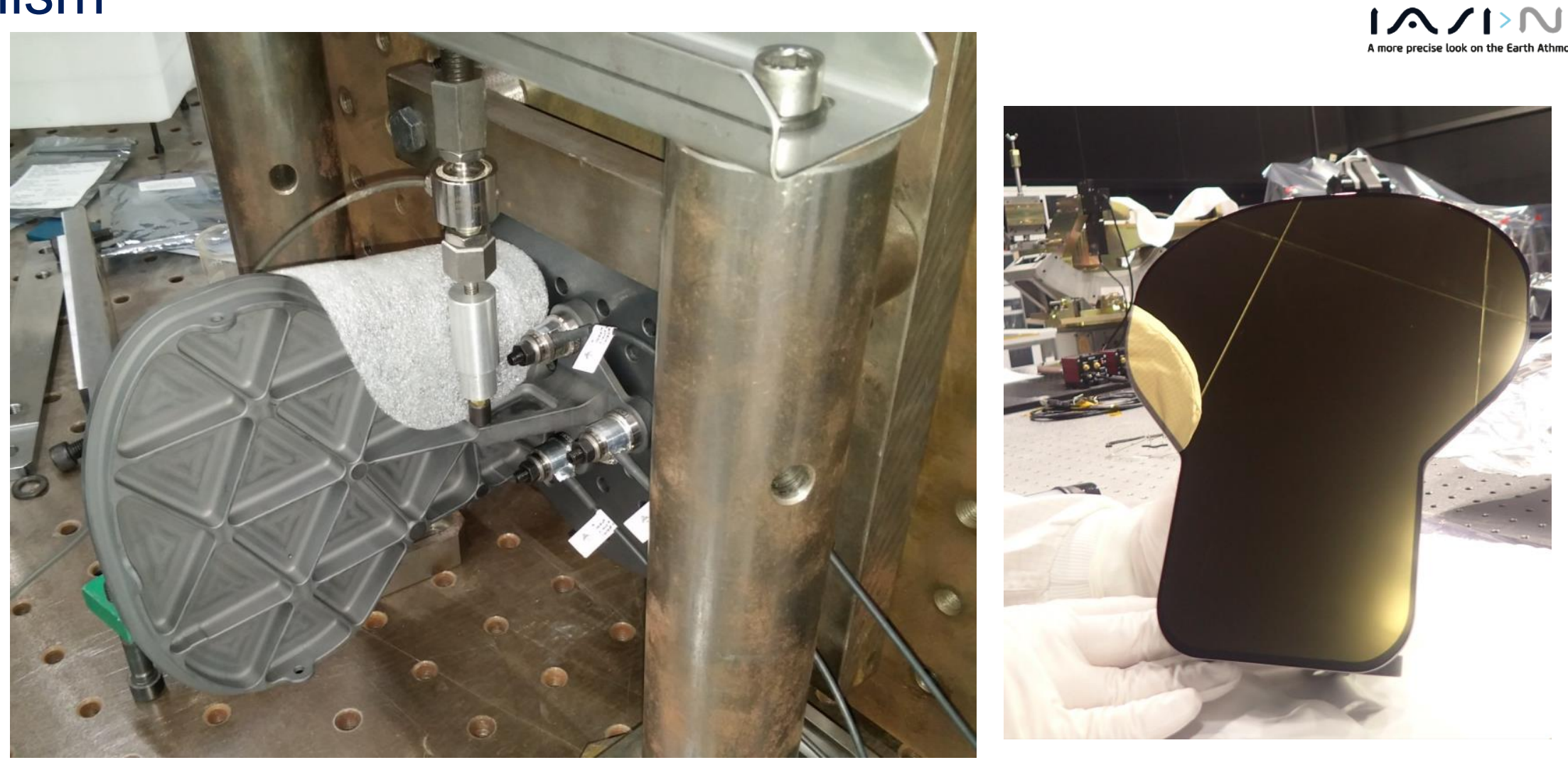

Silicon Carbide Pointing mirror blank ... and polished/coated mirror.

The pointing mirror mechanism is designed and manufactured with COMAT.

Its two axes motion (Across track Scan and satellite Velocity Compensation) is based on a concept patented by Airbus DS. The SiC mirrors are manufactured by BOOSTEC and polished and coated by REOSC. 


\section{Future activities}

- Delivery of the Structural and Thermal Model: end 2018

- Nearly all EM electronics available, in particular the detection chain

- Interferometer Assembly vacuum performance tests: Q2 2019

- Focal Plane and Cryo-cooler Assembly performance and qualification tests : Q2 2019



Key Millestones - Phase B2CD

\begin{tabular}{|l|l|}
\hline Kick Off & November 2013 \\
\hline PDR & April 2015 \\
\hline CDR & Q2 2019 \\
\hline
\end{tabular}

Delivery

PFM Q1 2020

FM2 Q1 2021

FM3 Q1 2022

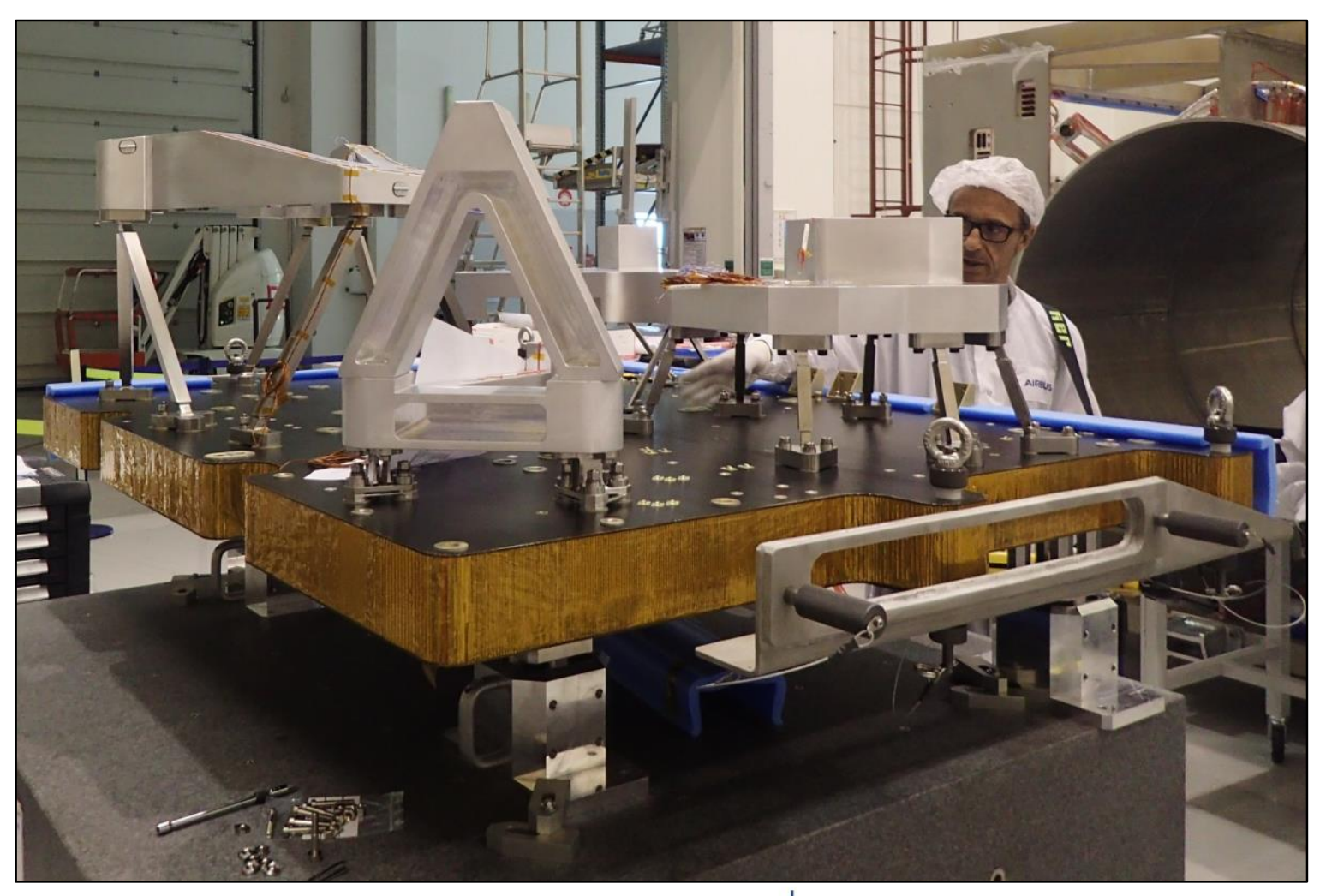

C

- cnes . 
Thank you 